\title{
Evaluation of Blackgram (Vigna mungo L.) Genotypes for their Tolerance to Flooding
}

\author{
M. S. Rana ${ }^{1}$, M. A. Hossain ${ }^{3}$, T. A. Urmi ${ }^{2}$, S. Ahmed ${ }^{4}$, M. M. Haque ${ }^{1}$ and M. M. Islam ${ }^{1} *$ \\ ${ }^{I}$ Departments of Agronomy and ${ }^{2}$ Soil Science, Bangabandhu Sheikh Mujibur Rahman Agricultural \\ University, Gazipur-1706, Bangladesh; ${ }^{3}$ Department of Soil Science, Bangladesh Agricultural \\ Research Institute, Gazipur-1701, Bangladesh; ${ }^{4}$ Department of Agronomy, Sher-e-Bangla Agricultural \\ University, Dhaka-1207, Bangladesh
}

*Corresponding author and Email: moshiul@bsmrau.edu.bd

Received: 14 July 2019

Accepted: 09 November 2019

\begin{abstract}
Waterlogging is one the major abiotic stresses that affects growth and yield of blackgram. A field experiment was carried out at the experimental field of Bangabandhu Sheikh Mujibur Rahman Agricultural University, Gazipur, 1706 during kharif II season to evaluate 26 blackgram genotypes for understanding the flood tolerance in respect of yield and yield contributing characters. The experiment was laid out with a randomized complete block design with three replications. Water logging depth was $3-5 \mathrm{~cm}$, created by irrigation from tap water and imposed at 29 days after emergence of seedlings which was maintained for 8 days. Multivariate analysis was performed involving eight qualitative plant characters. A wide range of variation was found for all the qualitative plant characters like plant height, plant dry weight, branches per plant, pods per plant, pod length, seeds per pod, 1000-seed weight and yield per plant. Flooding reduced all the growth parameters of blackgram but degree of reduction varied greatly over the blackgram genotypes. Considering yield performance, the genotypes BU Acc 25 showed the highest yield per plant $(9.03 \mathrm{~g})$ followed by the BU Acc $17(6.47 \mathrm{~g})$ and BU Acc 24 (6.17) under flooding. The yield reduction percent of the same genotypes were minimum $(43.86,60.82$ and 65.96 , respectively) compared to control which is very important for selection of those genotypes as a flooding tolerant.
\end{abstract}

Keywords: Genotypes, variability, flooding, blackgram.

\section{Introduction}

Blackgram (Vigna mungo L.) is a self-pollinated and widely cultivated grain legume (Nagarjuna et al., 2001). It is grown in cropping systems as a mixed crop, cash crop, sequential crop besides growing as sole crop under residual moisture conditions after the harvest of rice and also before and after the harvest of other summer crops under semi irrigated and dry land conditions (Parveen et al., 2011). Blackgram is an important pulse ranking the fourth both in hectares and production among the pulses (BBS, 2014). Locally it is known as maskalai which grows well in north or north-west part of Bangladesh. Blackgram is one of the rich sources of vegetable protein and some essential mineral and vitamins for human body. Among the various pulses, blackgram is an important one which contains approximately $25-28 \%$ protein, 4.5-5.5\% ash, $0.5-1.5 \%$ oil, $3.5-4.5 \%$ fibre and $62-65 \%$ carbohydrate on dry weight basis. It contains sulphur containing amino acids, methionine and cysteine and also contains lysine, 
which are excellent component of balanced human nutrition. The dried seeds are used to make dal, soups, and curries and added to various spiced or fried dishes. In spite of its various uses, its cultivation is decreasing day by day both in acreage and yield (BBS, 2014). In Bangladesh it can be grown both in summer and winter seasons. However, summer cultivation is better because excessive growth with higher number of pods and seeds occurs when the crop is grown in summer. The major constraints in achieving higher yield of this crop are lack of genetic variability, absence of suitable genotypes for different cropping system, poor harvest index and susceptibility to disease. Lack of suitable varieties and genotypes with adaptation to local condition is among the factors that affects the production.

In Bangladesh, blackgram is usually grown under rain fed condition where crop damage is common. Excessive rains can cause massive damage to the plant and delaying growth (Amin et al., 2016). Pounding of water due to rainfall, particularly in clay soil hampers root respiration. The problem is wide spread under flash flood due to climate change. A complete crop failure due to flooding is not uncommon. In general, grain legumes are somewhat tolerant to deficit water (Morton et al., 1982; Rosario and Faustino, 1985; Prakash et al., 2018) but susceptible to excess water (Miah et al., 1991; Bansal et al., 2019). Islam et al. (2007) observed the variability in tolerance of mungbean genotypes when subjected to variable levels of flooding. But such information on blackgram is very scanty. Flooding is an environmental stress that negatively influences germination, seedling establishment and plant development, as it causes a limitation in the flux of oxygen to support plant respiration. The effect of flooding on plant is obviously a reduced exchange of gasses between the plants and the environment (Maberly and Spense, 1989). Oxygen deficiency is the main constraint for plants have to deal with in a flooded situation (Crawford and Brandle, 1996). Flooding-induced stress may affects directly on the guard cell causing stomal closure and reduces photosynthetic capacity of plants (Bradford and Hsiao, 1982). Root damage of field crops under flooded condition is common phenomena although development of adventitious roots may occur in some crop species to sustain the growth under unfavourable conditions (Wenkert et al., 1981). Such genotypic variation in flooding tolerance mechanism of blackgram need to be elucidated, so that flood tolerant variety can be developed for unfavorable environmental conditions. Increase of pulse production is highly needed to meet up local demand, reduce import, save foreign currency and will increase price consumption. Considering the significance of blackgram in Bangladesh the present research is planned to screen flood tolerant genotype for the improvement of pulse crop.

\section{Materials and Methods}

The experiment was conducted in the Department of Agronomy, Bangabandhu Sheikh Mujibur Rahman Agricultural University (BSMRAU), Gazipur-1706 during kharif II season. It is located in Madhupur Tract under Agro Ecological Zone (AEZ) 28 at geographic coordinate $24^{0} 05^{\prime}$ North latitude and $90^{\circ} 16^{\prime}$ East longitude with an elevation of $8.4 \mathrm{~m}$ above the mean sea level. The soil of the experimental pot is silty clay. The site is situated in the subtropical region characterized by heavy rainfall during monsoon at the months from May to September and light rainfall in the rest of the months of the year. The soil of experimental pot was collected before sowing of seeds. Soil used in the plastic pot was silt clay.

\subsection{Treatments of the experiment}

The experiment was laid out in a randomized complete block design (RCBD) with two treatments where each treatment replicated three times. Two treatments such as (i) no flooding (Control) \& (ii) flooding were used in the experiment. Twenty six blackgram genotypes were used in the experiment. A list of genotypes with their origin is given in table 1. Flooding was imposed 29 days after emergence (DAE) at pre- 
flowering stage. Flooding depth was $3-5 \mathrm{~cm}$, created by irrigation from tap water which was maintained for 8 days. Pot was made completely non-perforated so water could not leach out. The water was made turbid twice daily by mixing mud. This was done to ensure that the conditions were made as similar as possible to the conditions which occur during actual flooding in nature. Flooding was stopped at 37 DAE. During the treatment period, dying of plant visually observed every day. In non-stress treatment, 100 $\%$ field capacity was maintained.

\subsection{Fertilizer application}

Recommended dose of fertilizer for Blackgram according to BARI was maintained (BARI, 2017). Urea: 40-50 kg/ha, Triple super phosphate: $90-95 \mathrm{~kg} / \mathrm{ha}$, Muriate of Potash: 30$40 \mathrm{~kg} / \mathrm{ha}$, Gypsum $60 \mathrm{~kg} / \mathrm{ha}$ Zinc sulphate 6 $\mathrm{kg} / \mathrm{ha}$. Half of urea, total amount of TSP, MOP, gypsum and zinc sulphate was applied at the time of final pot preparation. Rest amount of urea was top dressed at 15 days after first application. Intercultural operations such as weeding and thinning were done uniformly in each plot to ensure normal growth of the crop. To protect the plant from noxious insects Ripcord 10 EC @ 1 ml/liter of water was sprayed. Pods were harvested at 65 DAE when more than $80 \%$ pods were physiologically matured (turned blackish and got hard). After collecting of pods the sample plants were kept in the oven dry for 72 hours. The yield data such as plant height, branches per plant, plant dry weight, pods per plant, pod length, seeds per pod, 1000-seed weight and yield per plant were recorded from each plant of two treatments.

Table 1: Blackgram genotypes used in this experiment with their source

\begin{tabular}{ccc}
\hline Genotype No. & Accession code & Source \\
\hline G1 & BU Acc 1 & Rajshahi \\
G2 & BU Acc 2 & Chapai Nobabgonj \\
G3 & RU Acc 3 & Rajshahi \\
G4 & BU Acc 4 & Chapai Nobabgonj \\
G5 & BU Acc 5 & Chapai Nobabgonj \\
G6 & BU Acc 6 & Chapai Nobabgonj \\
G7 & BU Acc 7 & Rajshahi \\
G8 & BU Acc 8 & Chapai Nobabgonj \\
G9 & BU Acc 9 & Chapai Nobabgonj \\
G10 & BU Acc 10 & Chapai Nobabgonj \\
G11 & BU Acc 11 & Chapai Nobabgonj \\
G12 & BU Acc 12 & Chapai Nobabgonj \\
G13 & BU Acc 13 & Chapai Nobabgonj \\
G14 & BU Acc 14 & Rajshahi \\
G15 & BU Acc 15 & Rajshahi \\
G16 & BU Acc 16 & Chapai Nobabgonj \\
G17 & BU Acc 17 & Chapai Nobabgonj \\
G18 & BU Acc 18 & Chapai Nobabgonj \\
G19 & BU Acc 19 & Chapai Nobabgonj \\
G20 & BU Acc 20 & Chapai Nobabgonj \\
G21 & BU Acc 21 & Chapai Nobabgonj \\
G22 & BU Acc 22 & Chapai Nobabgonj \\
G23 & BU Acc 23 & Rajshai University \\
G24 & BU Acc 24 & Chapai Nobabgonj \\
G25 & BU Acc 25 & Chapai Nobabgonj \\
G26 & BARI mash-3 Check variety) & BARI \\
\hline
\end{tabular}



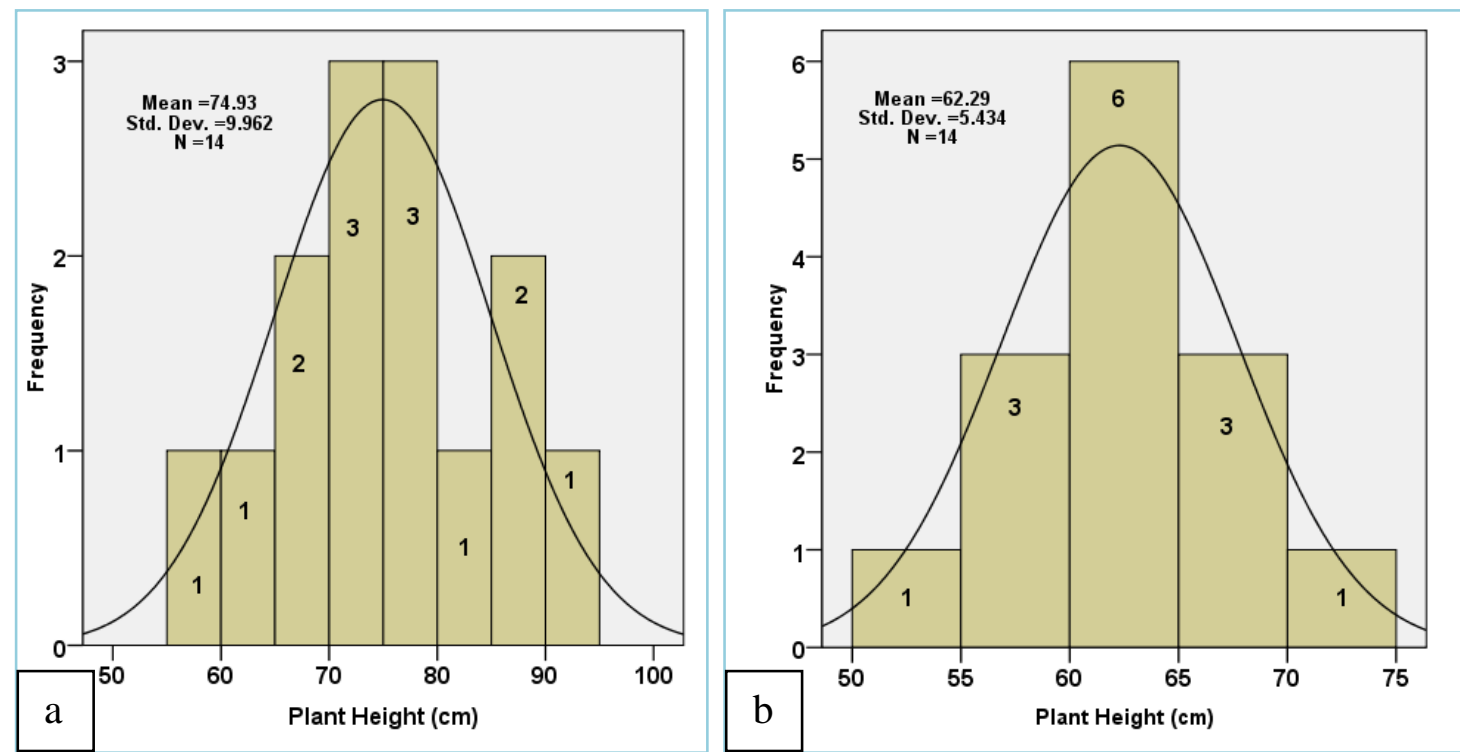

Figure 1. Frequency distribution of plant height of fourteen blackgram genotypes under (a) control and (b) flood condition

\subsection{Statistical analysis}

Analysis of genetic variation among genotypes was performed with the program SPSS 16. Eight qualitative variables were enlisted before considered in the cluster analysis.

\section{Results and Discussion}

Twenty six blackgram genotypes (Table 1) were subjected into two different treatments, viz. control (regular irrigation) and flood (at pre flowering stage). After 8 days of flooding, twelve genotypes were totally died. The twelve died genotypes are G1 (BU Acc 1), G2 (BU Acc 2), G4 (BU Acc 4), G6 (BU Acc 6), G7 (BU Acc 7), G8 (BU Acc 8), G9 (BU Acc 9 ), G10 (BU Acc 10), G12 (BU Acc 12), G13 (BU Acc 13), G16 (BU Acc 16) and G18 (BU Acc 18). As the objective is to screen out the flood tolerant blackgram genotypes so survived genotypes under flooding were considered for analysis of the data. Thus, fourteen survived genotypes (G3, G5, G11, G14, G15, G17, G19, G20, G21, G22, G23, G24, G25 and G26) were finally used in cluster analysis under both control and flood condition.

\subsection{Plant height}

Plant height ranged between $59.33 \mathrm{~cm}$ and 90.30 $\mathrm{cm}$ with a mean of $74.93 \mathrm{~cm}$ in control where $53.00 \mathrm{~cm}$ and $72.50 \mathrm{~cm}$ with a mean of $62.30 \mathrm{~cm}$ under flood condition. In control the frequency distribution of plant height showed almost normal distribution with slightly skewed towards left $(\alpha=-0.01)$ indicating that most of the genotypes were more than median (Fig. 1a). Among the fourteen genotypes, the plant height of four genotypes ranged from $50 \mathrm{~cm}$ to $70 \mathrm{~cm}$. Plant height of six genotypes ranged from $70 \mathrm{~cm}$ to $80 \mathrm{~cm}$ and four genotypes showed plant height more than $80 \mathrm{~cm}$ (Fig. 1a). Under flood condition the frequency distribution of plant height showed almost normal distribution with slightly skewed towards right $(\alpha=0.29)$ indicating that most of the genotypes were more than median (Fig. 1b). Among the fourteen genotypes, the plant height of four genotypes ranged from $50 \mathrm{~cm}$ to $60 \mathrm{~cm}$, six genotypes ranged from $60 \mathrm{~cm}$ to $65 \mathrm{~cm}$ and four genotypes showed plant height more than $65 \mathrm{~cm}$ (Fig. 1b). The above results show that plant height was decreased due to flood. However, under flood condition the highest plant height was found in 
G15 followed by G17 and G14. The lowest plant height was found in G20 followed by G24 and G26. Amin et al. (2016) observed that the height of mungbean plant decreased under flooding. The variation in plant height might be due to varietal characters of genotypes and adverse effects of continuous 8 days waterlog condition.

\subsection{Plant dry weight}

Flooding generally reduced the growth of plant components resulting in lesser plant dry weight. Plant dry weight ranged between $4.68 \mathrm{~g}$ and 9.90 $\mathrm{g}$ with a mean of $8.30 \mathrm{~g}$ at control but $4.68 \mathrm{~g}$ and $9.10 \mathrm{~g}$ with a mean of $6.87 \mathrm{~g}$ at flood condition. The frequency distribution of plant dry weight showed almost normal distribution with slightly skewed towards left $(\alpha-1.28)$ indicating that most of the genotypes were more than median at control (Fig. 2a) where slightly skewed towards right $\left(\begin{array}{ll}\alpha & 0.17\end{array}\right)$ indicating that most of the genotypes were less than median (Fig. 2b). In control the plant dry weight of seven genotypes ranged from $4.0 \mathrm{~g}$ to $9.0 \mathrm{~g}$ and seven genotypes ranged from $9 \mathrm{~g}$ to $10 \mathrm{~g}$ (Fig. 2a) where at

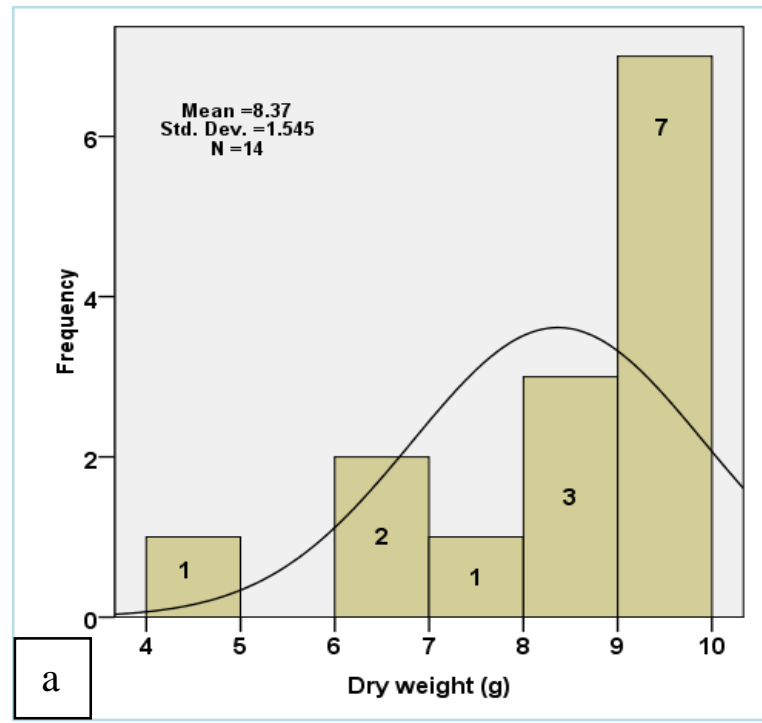

flooding conditions, seven genotypes ranged from $4.0 \mathrm{~g}$ to $7.0 \mathrm{~g}$ and seven genotypes ranged from $7 \mathrm{~g}$ to $10 \mathrm{~g}$ (Fig. 2b). Compare to the control, the reduction in plant dry weight was lower in the genotypes G5 followed by G24 and G3 under flooding. The impact of flooding on fresh and dry weight of three legume plants, namely faba bean, common bean and pea plants showed that dry matter accumulation of shoots and roots were significantly decreased in waterlogging (El-Enany et al., 2014).

\subsection{Branch number per plant}

Number of branch per plant ranged between 4.50 and 7.67 with a mean of 6.02 in control and between 3.00 and 6.33 with a mean of 4.50 in flood condition. At control condition the frequency distribution of branch number per plant showed positively skewed towards right ( $\alpha$ $=0.29$ ) indicating that most of the genotypes were less than median (Fig. 3a) where at flood condition negatively skewed towards right $(\alpha=$ 0.22 ) indicating that most of the genotypes were more than median (Fig. 3b).

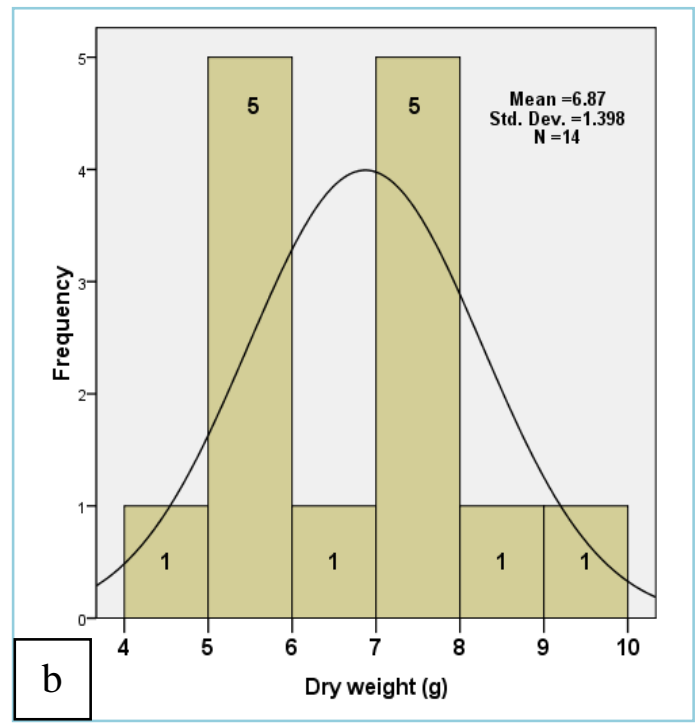

Figure 2. Frequency distribution of plant dry weight of fourteen blackgram genotypes under (a) control and (b) flood condition 

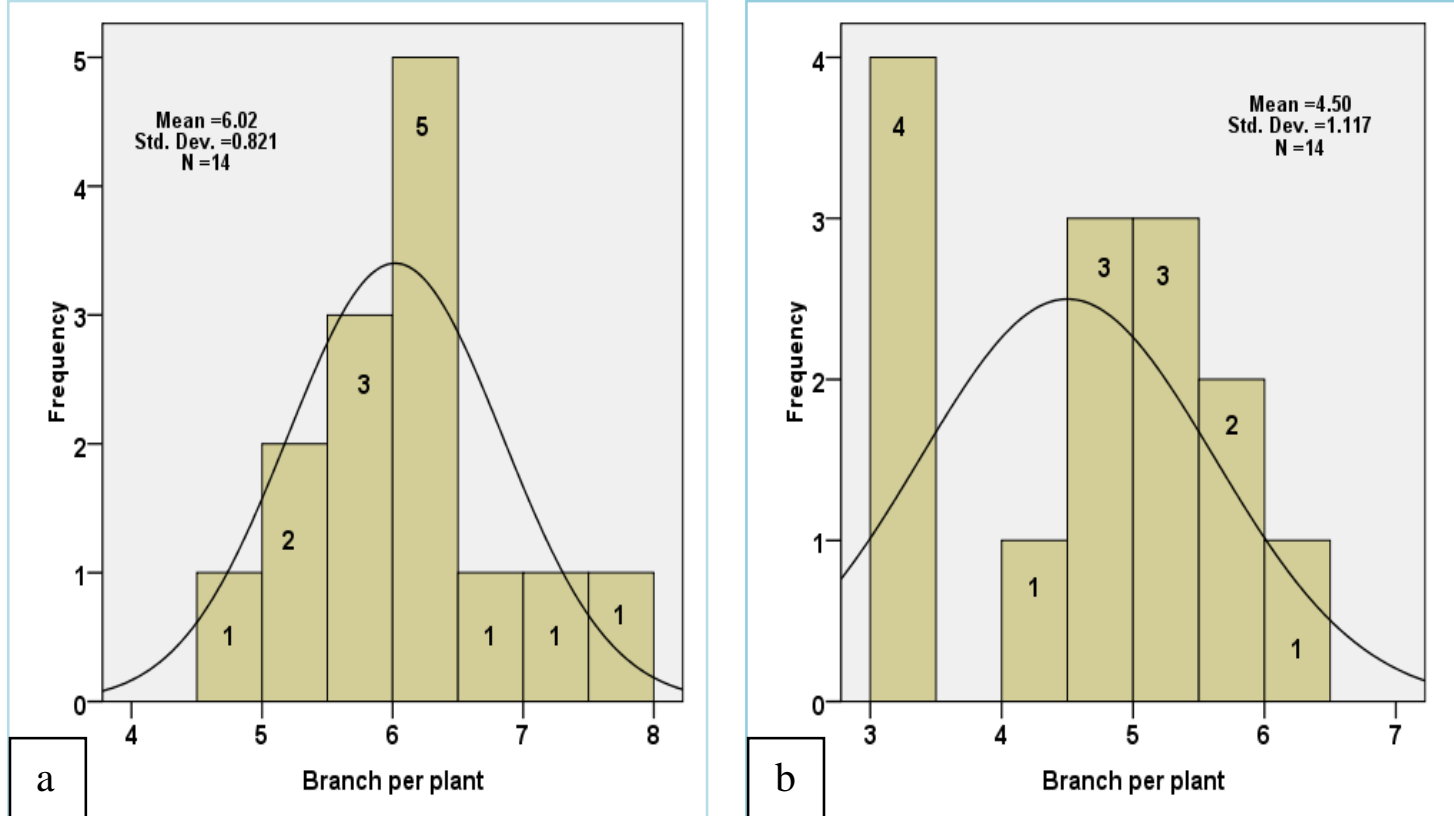

Figure 3. Frequency distribution of branch per plant of fourteen blackgram genotypes under (a) control and (b) flood condition
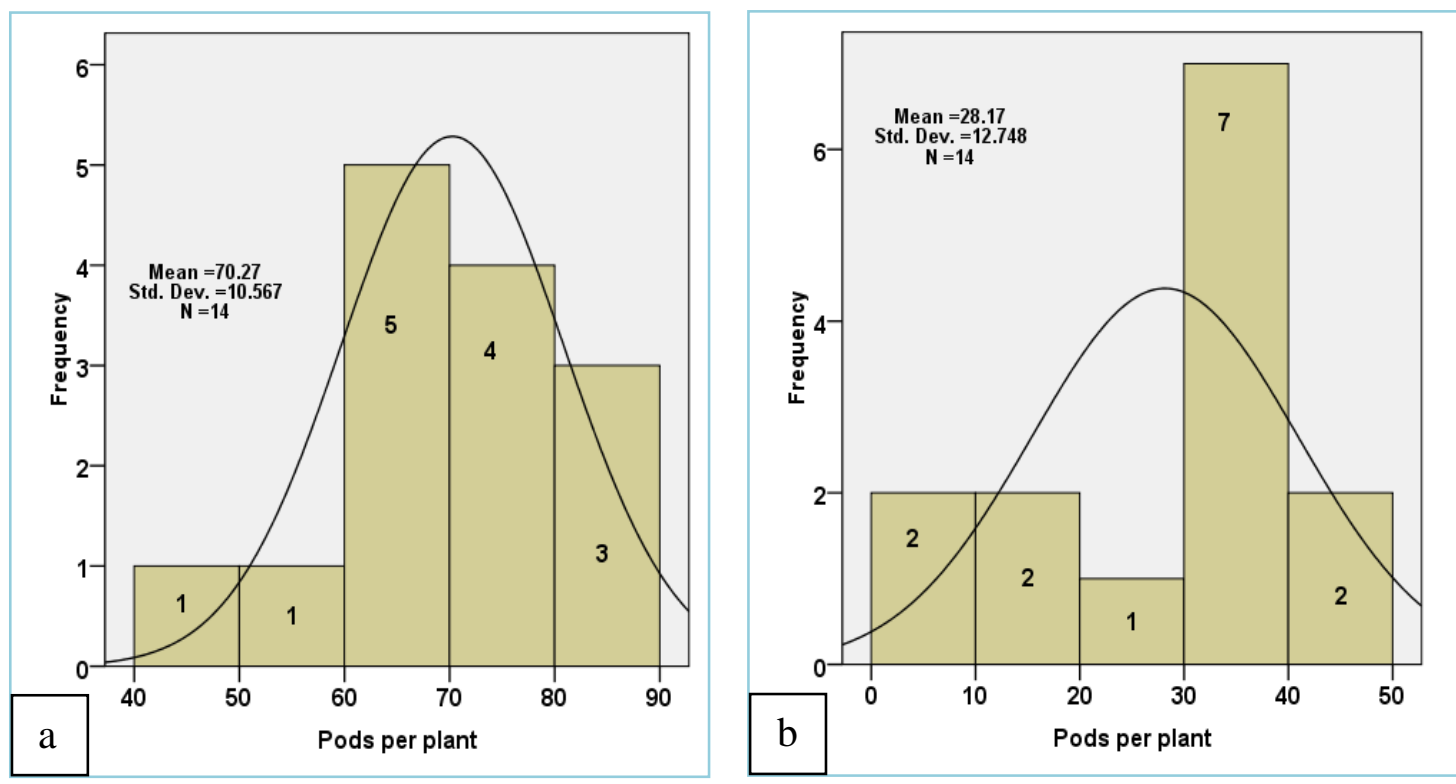

Figure 4. Frequency distribution of pods per plant of the fourteen genotypes under (a) control and (b) flood condition

In control the branch number per plant of six genotypes ranged from 4.0 to 6.0 , six genotypes ranged from 6 to 7 and two genotypes showed

branch per plant more than seven (Fig. 3a). At flood condition the branches number per plant of four genotypes ranged from 3.0 to 4.0 and ten 
genotypes ranged from 4.0 to 7.0 (Fig. 3b). This results indicate that branches number per plant were decreased due to flooding. However, under flooding condition the highest branches number per plant was found in G25 followed by G3 and G24. Amin et al. (2016) found that branches number per plant was decreased due to flooding in mungbean. The branching habit of a plant is genetically determined and it was reduced significantly when plants were waterlogged for variable periods. Minchin et al. (1978) demonstrated that the yield reduction by waterlogging at the vegetative stage of cowpea was closely related to the reduction of lateral shoot development. The reduction of branch plant $^{-1}$ might be due to the competition of assimilates between roots and the other organs in waterlogging affected plants reported by Nawata (1989).

\subsection{Number of pods per plant}

At control condition, pod numbers per plant of the genotypes were found in a range between

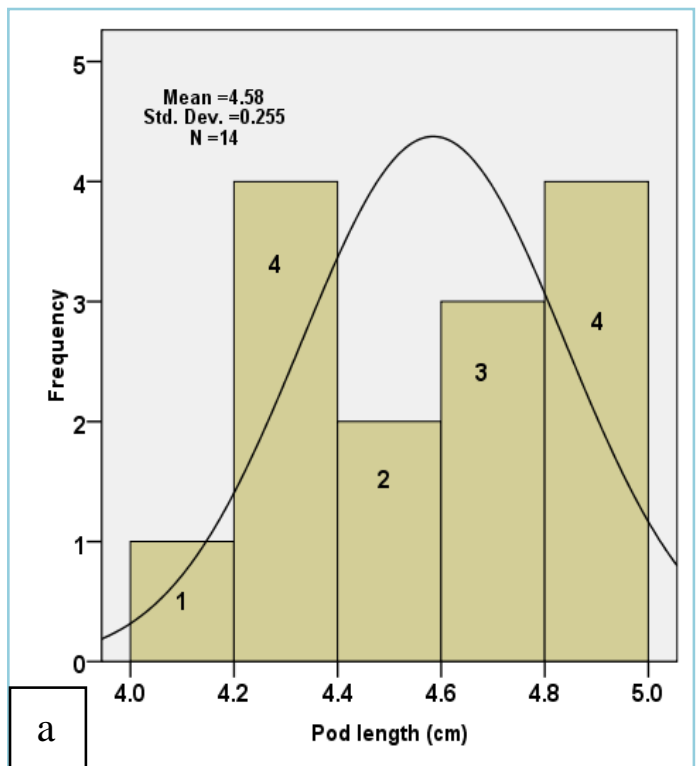

47.00 and 85.50 with an average of 70.27 but 7.50 and 47.50 with an average of 28.20 at floodingcondition. The frequency distribution of pods per plant showed a normal distribution curve with skewed towards right $(\alpha=-0.62)$ and $(\alpha=-0.49)$ at control and at flooding conditions indicating most of the genotypes were more than the median (Fig. 4a \& 4b). At control condition seven genotypes showed pods per plant within 40 to 70 and four genotypes showed pods per plant between 70 and 80 . Three genotypes showed more than 80 pods per plant (Fig. 6a). At flooding condition five genotypes showed pods per plant within 0 to 30 and seven genotypes showed pods per plant between 30 and 40. Two genotypes showed pods per plant more than 40 (Fig. 4b). The results show that pod numbers per plant were decreased due to flooding. However, under flood condition the highest pod numbers per plant was found in G25 followed by G26 and G3. Amin et al. (2017) reported that the number of pods plant ${ }^{-1}$ in mungbean affected significantly due to waterlogging stress.

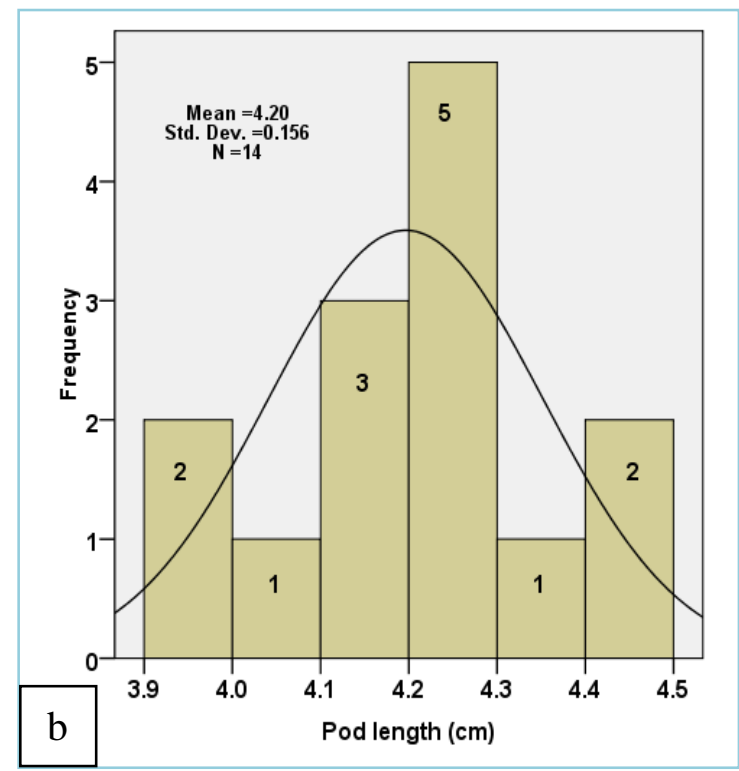

Figure 5. Frequency distribution of pod length of the fourteen blackgram genotypes under (a) control and (b) flood condition 

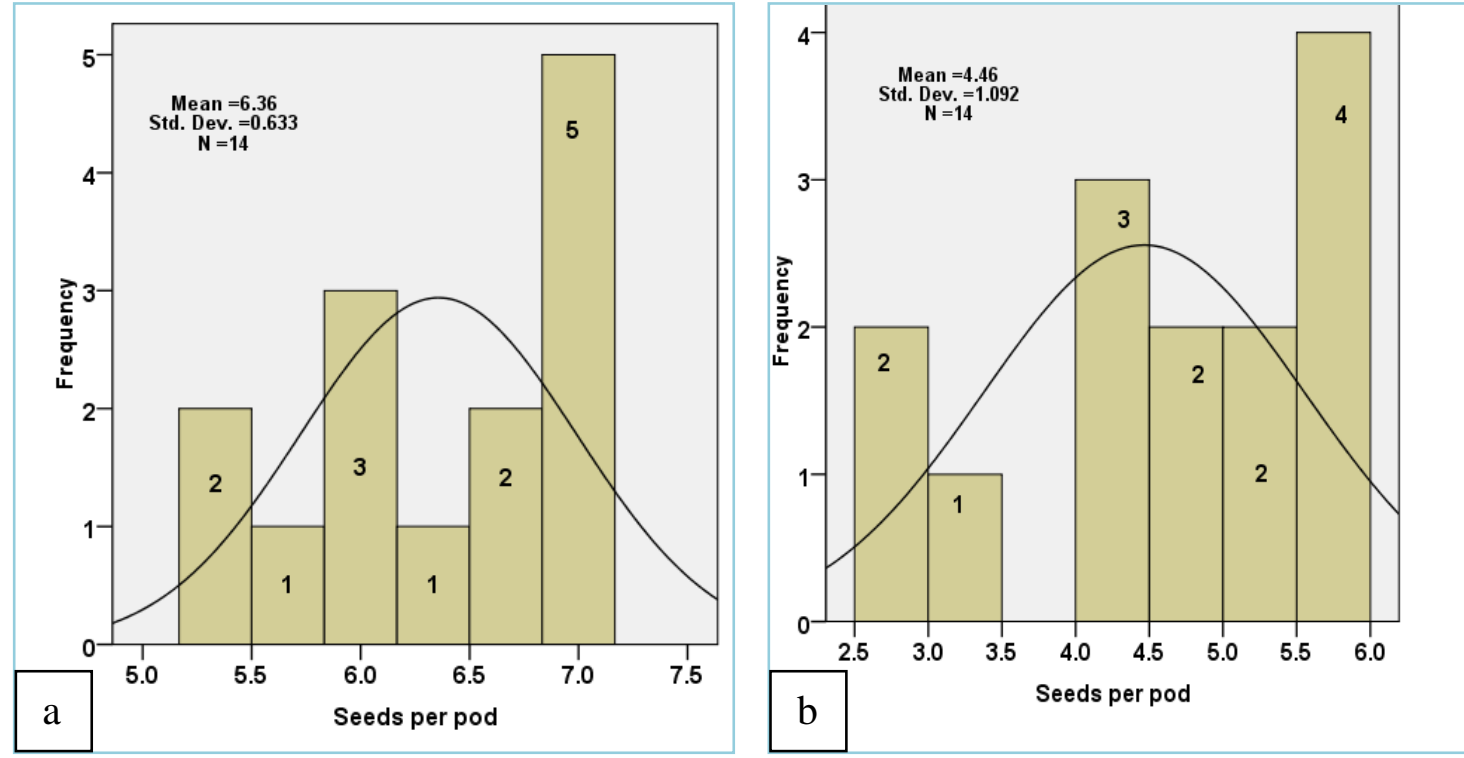

Figure 6. Frequency distribution of seeds per pod of the fourteen blackgram genotypes under (a) control and (b) flood condition
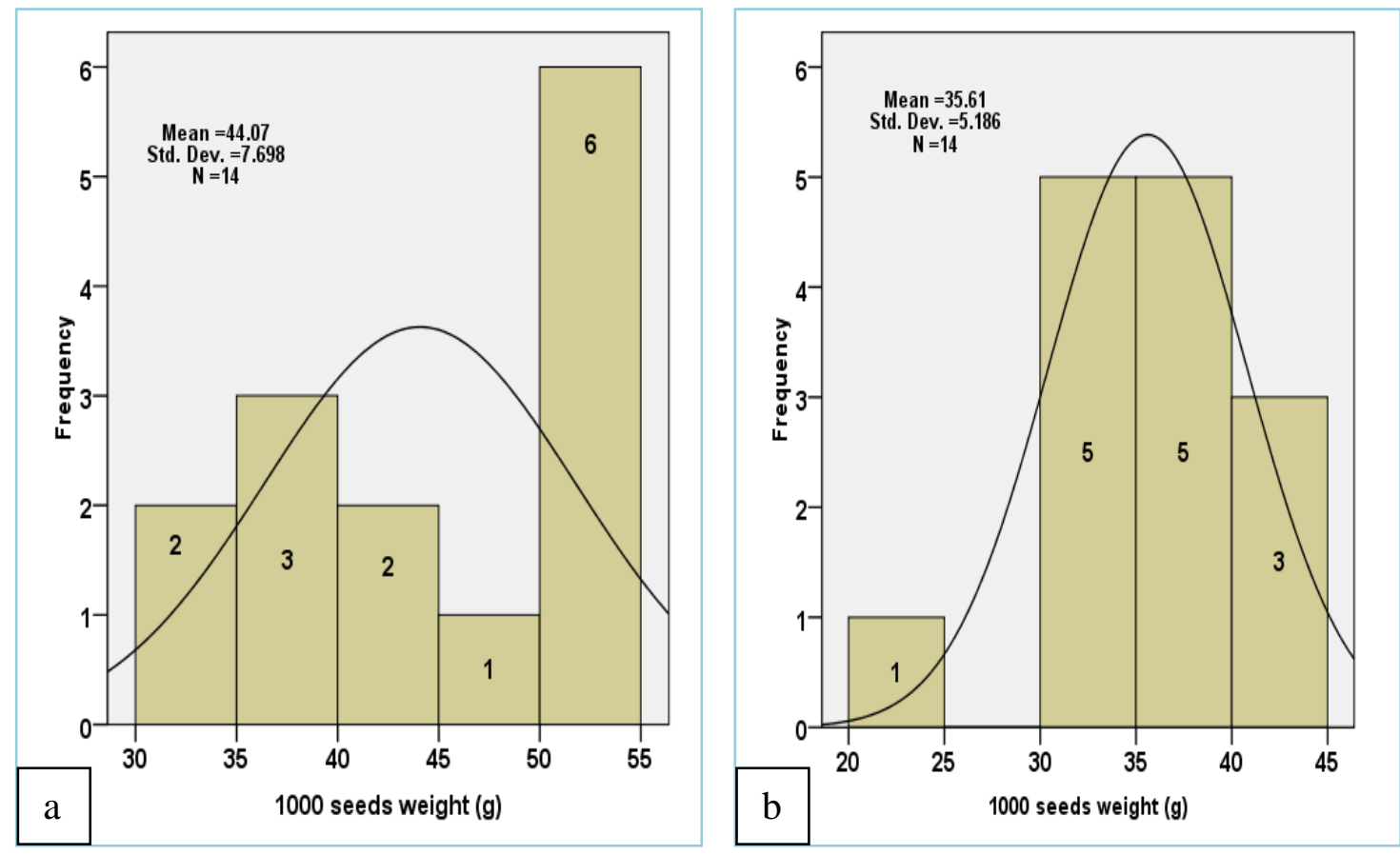

Figure 7. Frequency distribution of 1000-seeds weight of the fourteen blackgram genotypes under (a) control and (b) flood condition 
Umaharan et al. (1997) reported that waterlogging during the vegetative period resulted in a significant decline in pod yield of cowpea and the reductions reflected in the number of pod plant ${ }^{-1}$. Similarly Nawata et al. (1991) reported that in yard long bean, the yield reduction in plants subjected to long-term waterlogging was due to reduction in pod number plant $^{-1}$.

\subsection{Pod length}

Pod lengths of the genotypes in control were found in a range between $4.16 \mathrm{~cm}$ and $4.92 \mathrm{~cm}$ with an average of $4.58 \mathrm{~cm}$. which was $3.91 \mathrm{~cm}$ and $4.44 \mathrm{~cm}$ with an average of $4.20 \mathrm{~cm}$ under flood. The frequency distribution of pod length showed a normal distribution curve with skewed towards right $(\alpha=-0.29)$ and $(\alpha=-0.27)$ in control and in flood indicating the most of the genotypes were more than the median (Fig. 5a \& 5b). At control seven genotypes showed pod length between $4.0 \mathrm{~cm}$ and $4.6 \mathrm{~cm}$ and fifty percent (seven) genotypes showed pod length between $4.6 \mathrm{~cm}$ and $5.0 \mathrm{~cm}$ (Fig. 5a). At flooding condition six genotypes showed pod length between $3.9 \mathrm{~cm}$ to $4.2 \mathrm{~cm}$, five genotypes showed pod length between $4.2 \mathrm{~cm}$ and $4.3 \mathrm{~cm}$ and three genotypes showed pod length between $4.3 \mathrm{~cm}$ and 4.5 (Fig. 5b). The results show that pod length was decreased due to flooding. However, the highest pod length was found in G3 followed by G17 and G21 under flood condition. Islam (2003) reported that pod length of mungbean was affected significantly due to waterlogging stress.

\subsection{Seed per pod}

Seed numbers per pod of the genotypes at control condition were found in a range between 5.33 and 7.00 with an average of 6.36 where 2.50 and 5.67 with an average of 4.46 at flooding condition. The frequency distribution of seeds per pod showed a normal distribution curve with skewed towards left $(\alpha=-0.43)$ and left $(\alpha=$ 0.69 ) at control and flooding conditions indicating most of the genotypes were more than the median (Fig. 6a \& 6b). At control condition seeds per pod of seven genotypes ranged from
5.0 to 6.5 and 6.5 to 7.5 for other seven genotypes (Fig. 6a). At flooding condition six genotypes showed seeds per pod between 2.5 to 4.5, four genotypes showed seeds per pod between 4.5 to 5.5 and four genotypes showed seeds per pod between 5.5 to 6.0 (Fig. 6b). The above results show that seed numbers per pod were decreased due to flooding. However, under flood condition the highest seed numbers per pod was found in G17 followed by G3 and G25 and the lowest seed numbers per pod was found in G21 followed by G22 and G3.

Islam (2003) did not find any significant difference on the number of seed pod $^{-1}$ due to waterlogging at different growth stages as a well as across mungbean genotypes. However, Amin et al. (2017) reported that Irrespective of genotypes, the number of seed pods ${ }^{-1}$ in mungbean affected significantly due to waterlogging stress.

\subsection{Thousand seeds weight}

At control condition, thousand seed weight ranged between $31.96 \mathrm{~g}$ and $53.46 \mathrm{~g}$ with a mean of $44.07 \mathrm{~g}$ where $22.89 \mathrm{~g}$ and $43.03 \mathrm{~g}$ with a mean of $35.60 \mathrm{~g}$ at flood condition. The frequency distribution of 1000-seed weight showed almost normal distribution with highly skewed towards left $(\alpha=-0.35)$ and $(\alpha=-0.83)$ at control and flooding condition indicating that most of the genotypes were more than median (Fig. 7a \& 7b). At control condition 1000-seed weight of eight genotypes ranged from 30.0 to $50.0 \mathrm{~g}$ and six genotypes exhibited 1000-seed weight ranged from 50.0 to $55.0 \mathrm{~g}$. At flooding condition 1000-seed weight of six genotypes ranged from 20.0 to $35.0 \mathrm{~g}$ and eight genotypes exhibited 1000-seed weight ranged from 35.0 to $45.0 \mathrm{~g}$. The results show that 1000 -seed weight was decreased due to flooding. However, under flood condition the highest 1000-seed weight was found in G22 followed by G26 and G24 and the lowest 1000-seed weight was found in G5 followed by G11and G19. Amin et al. (2016) and Ahmed et al. (2002) also observed that 1000 -seed weight of mungbean plant decreased under flooding condition. 

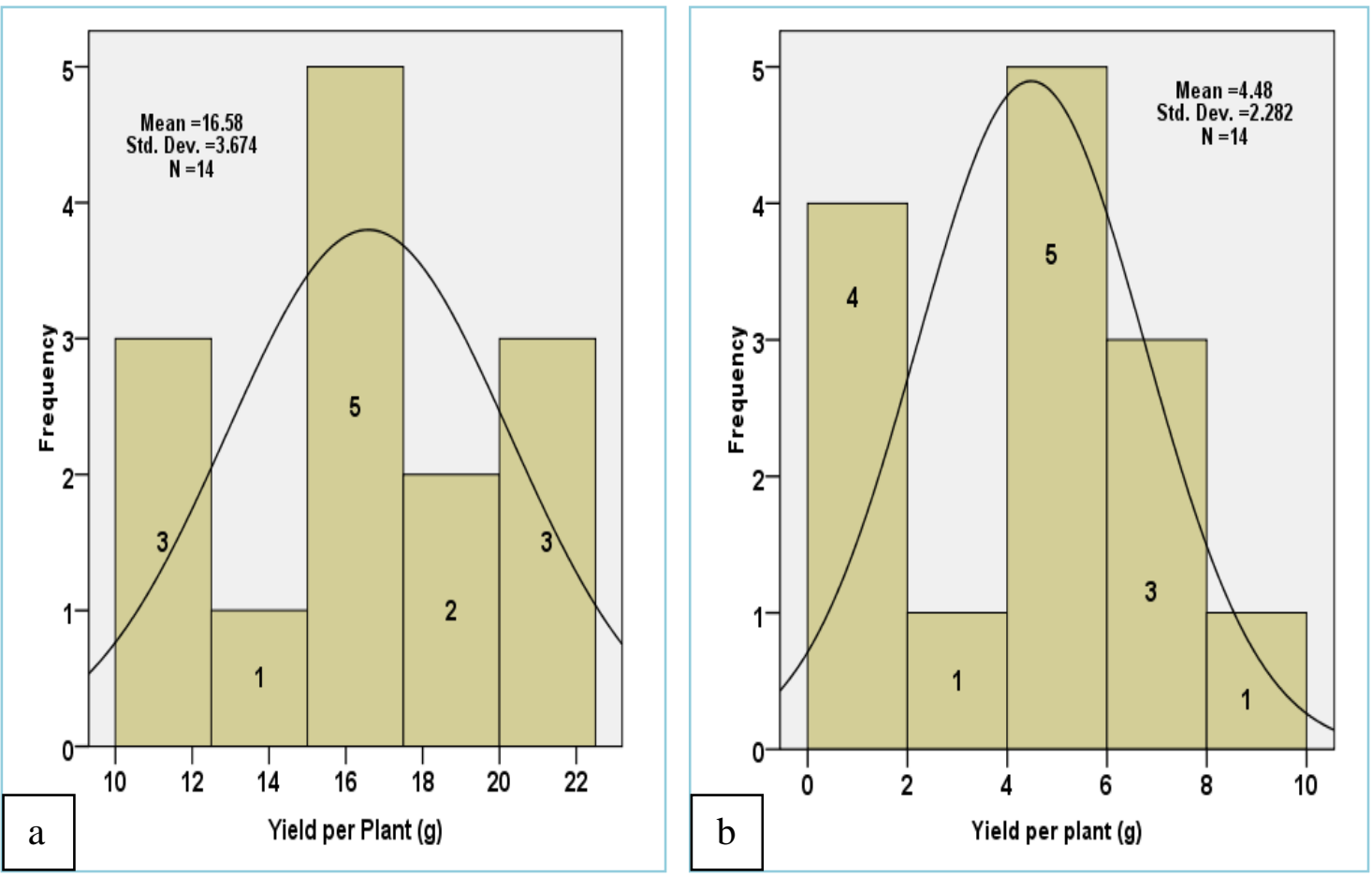

Figure 8. Frequency distribution of seed yield per plant $(\mathrm{g})$ of the fourteen blackgram genotypes under (a) control and (b) flood condition.

Table 2. Percent yield reduction of the higher yielded genotypes of blackgram subjected to flood condition

\begin{tabular}{ccccc}
\hline Genotype no. & Accession code & $\begin{array}{c}\text { Yield at control } \\
\text { (g/plant) }\end{array}$ & $\begin{array}{c}\text { Yield at flood } \\
\text { (g/plant) }\end{array}$ & $\begin{array}{c}\text { \% Yield } \\
\text { reduction }\end{array}$ \\
\hline G3 & BU Acc 3 & 22.20 & 4.62 & 79.20 \\
G5 & BU Acc 5 & 20.30 & 1.49 & 92.68 \\
G11 & BU Acc 11 & 19.20 & 5.63 & 70.69 \\
G14 & BU Acc 14 & 10.15 & 3.62 & 64.36 \\
G15 & BU Acc 15 & 14.09 & 4.51 & 67.97 \\
G17 & BU Acc 17 & 16.50 & 6.47 & 60.82 \\
G19 & BU Acc 19 & 17.21 & 1.99 & 88.44 \\
G20 & BU Acc 20 & 21.55 & 4.24 & 80.31 \\
G21 & BU Acc 21 & 16.15 & 1.14 & 92.92 \\
G22 & BU Acc 22 & 11.55 & 1.82 & 84.21 \\
G23 & BU Acc 23 & 11.87 & 5.77 & 51.40 \\
G24 & BU Acc 24 & 18.12 & 6.17 & 65.96 \\
G25 & BU Acc 25 & 16.09 & 9.03 & 43.86 \\
G26 & BARI mash-3(Check) & 17.12 & 6.21 & 63.73 \\
\hline
\end{tabular}


Islam (2003) reported a depression of 1000-seed weight in mungbean due to flooding. Similarly, Nawata et al. (1991) reported that one hundred seed weight of yard long bean was reduced by waterlogging treatments and was smallest in plants subjected to continuous waterlogging. It was probable that poor translocation of assimilates from source to sink resulted in smaller seed size.

\subsection{Seed yield}

In control, seed yield per plant ranged between $10.15 \mathrm{~g}$ and $22.20 \mathrm{~g}$ with a mean of $16.58 \mathrm{~g}$ which was $1.14 \mathrm{~g}$ and $9.03 \mathrm{~g}$ with a mean of 4.48 $\mathrm{g}$ under flood condition. The frequency distribution of seed yield per plant showed almost normal distribution with slightly skewed toward left $(\alpha=-0.25)$ indicating that most of the genotypes were in more than median (Fig. 8a) but slightly skewed toward right $(\alpha=0.13)$ under flood condition indicating that most of the genotypes were in less than median (Fig. 8b). The seed yield per plant of four genotypes ranged from $10.0 \mathrm{~g}$ to $15.0 \mathrm{~g}$ and five genotypes exhibited seed yield per plant ranged from $15.0 \mathrm{~g}$ to $18.0 \mathrm{~g}$, two genotypes showed seed yield per plant from $18 \mathrm{~g}$ to $20 \mathrm{~g}$ and three genotypes showed seed yield per plant more than $20 \mathrm{~g}$ (Fig. 8a). Five genotypes ranged from 0.0 to $4.0 \mathrm{~g}$, five genotypes exhibited seed yield per plant ranged from $4.0 \mathrm{~g}$ to $6.0 \mathrm{~g}$, three genotypes showed seed yield from $6.0 \mathrm{~g}$ to $8.0 \mathrm{~g}$ and only one genotype showed seed yield per plant more than $8.0 \mathrm{~g}$ (Fig. 8b).

Results shows in Table 2 indicated that some blackgram genotypes (G21, G5 and G22) were highly susceptible to flooding resulting in severe reduction in yield. The blackgram genotypes G25, G17 and G24 are found flood tolerant where yield reduction percent were $43.86,60.82$ and 65.96 , respectively in comparison to that in control (Table 2). Minchin et al. (1978) reported $48 \%$ loss in yield of cowpea in response to waterlogging during the vegetative phase under simulated tropical conditions. Nawata et al. (1991) observed significant reduction in seed yield of yard long bean (about $75 \%$ of the control) by long-term (16 days) waterlogging treatment. Islam (2003) reported that longer period of waterlogging significantly reduced the seed yield of mungbean. Wang et al. (2013) reported that yield loss due to waterlogging may vary between $15 \%$ and $80 \%$ depended on the crop species and growth stage, soil type and duration of the stress. Waterlogging reduced seed yield primarily by reducing the number of pods per plant and pod setting. Some of the cumulative effects of flooding i.e. closing of stomata, the increasing of ethylene and the declining of rubisco activity to decline crop growth rate (CGR), net assimilation rate (NAR), and leaf expansion rate (LER) of plants and finally reduced seed yield (Linkemer et al., 1998).

\section{Conclusions}

In all cases plants of control condition performs better compared to plants of flood condition. The performance of the plants is more pronounced in case of plant height, pods per plant and yield per plant. Under control condition G3 produced highest yield per plant followed by G20, and G5. On the other hand, under flood condition G25 produced highest yield per plant followed by G17, and G24. On the basis of yield and other factors G25, G17 and G24 consider as the best genotypes and they have a huge potentiality for developing a new flood tolerant variety.

\section{Acknowledgements}

We are most grateful to Director General, Bangladesh Bureau of Educational Information and Statistics (BANBEIS) as this research was supported by operating grants from "Grants for Advanced Research in Education", Ministry of Education, Dhaka-1205, Bangladesh.

\section{References}

Ahmed S., Nawata E., Sakuratani T. 2002. Effects of waterlogging at vegetative and reproductive growth stage on photosynthesis, leaf water potential yield 
in mungbean. Plant Production Science, 5(2): 117-123.

Amin MR., Karim MA., Islam MR., Aktar S., Hossain MA. 2016. Effect of flooding on growth and yield of mungbean genotypes. Bangladesh Journal of Agricultural Research, 41(1), 151-162.

Amin MR., Karim MA., Khaliq QA., Islam MR., Aktar S. 2017. The influence of Waterlogging Period on Yield and Yield Components of Mungbean (Vigna radiata L.Wilczek). The Agriculturists, 15(2): 88100.

BARI. 2017. Krishi Projockti Hatboi, Bangladesh Agricultural Research Institute. $7^{\text {th }}$ edition.

BBS. 2014. Bangladesh Bureau of Statistics. Ministry of Planning. Government of the People's Republic of Bangladesh.

Bradford KJ., Hsiao TC. 1982. Stomatal behavior and water relations of waterlogged tomato plants. Plant Physiology. 70: 1508-1513.

Crawford RMM., Brandle R. 1996. Oxygen deprivation stress in a changing environment. Journal of Experimental Botany, 47: 145-159.

El-Enany AE., Morsy F., Dief N. 2014. Impact of water stress on growth criteria and alcohol dehydrogenase activity of three legume plants. Minia Science Bulletin, 25(1): 29-51 and Flooding and plant growth. Orlando; Academic press.110128.

Islam MR., Hamid A., Khaliq QA., Ahmed JU., Haque MM., Karim MA. 2007. Genetic variability in flooding tolerance of mungbean (Vigna radiata L.) genotypes. Euphytica, 156: 247-255.

Islam MR. 2003. Eco-physiology of soilflooding tolerance in mungbean. A Ph.D. thesis. Bangabandhu Sheikh Mujibur Rahman Agricultural University, Salna, Gazipur1706, Bangladesh.
Linkemer G., Board IE., Musgrave ME. 1998. Waterlogging effects on growth and yield components in late-planted soybean. Crop Science, 38: 1576-1584.

Maberly SC., Spence DHN. 1989. Photosynthesis and photo-respiration in freshwater organisms: amphibious plants. Aquatic Botany, 34:267-286.

Miah AA., Moniruzzaman AFM., Rahman MM. 1991. Problems and prospects of pulses production. In: Kumar, J. (Eds.). Advances in pulses research in Bangladesh. Proceeding of the second national workshop on pulses. Joydebpur, Bangladesh.

Minchin FR., Summerfield RJ., Eaglesham ARJ., Stewart KA. 1978. Effects of shortterm waterlogging on growth and yield of cowpeas (Vigna unguiculata). Journal of Agricultural Science, Cambridge University Press. 90:355-366.

Morton JF., Smith RE., Poehlman JM. 1982. The mungbean. University of Puerto Rice. Mayaguez.

Nagarjuna M., Sagar K., Sekhar MR. 2001. Character association studies in black gram (Vigna mungo L. Hepper). Madras Agricultural Journal, 88: 222-224.

Nawata E. 1989. Analysis of the responses of yard long bean to waterlogging. A Ph.D. thesis. Kyoto University, Japan.

Nawata E., Yoshinaga S., Shigenaga S. 1991. Effects of waterlogging duration on the growth and yield of yard long bean (Vigna sinensis var. sesquipedalis). Elsevier Science Publishers B.V. Scientia Horticulturae, 48:185-191.

Parveen S., Sekhar, MR., Reddy DM., Sudhakar, 2011. Correlation and path coefficient analysis for yield and yield Components in blackgram (Vigna mungo I.Hepper). International Journal of Applied Biology and Pharmaceutical Technology, 2: 616623. 
Rosario DDA., Faustino FC. 1985. Screening of drought resistance in mungbean. In Proceeding of the workshop on varietal improvement for rice based farming systems. Thailand.

Umaharan P., Ariyanayagam RP., Haque SQ. 1997. Effect of short-term waterlogging applied at various growth phases on growth, development and yield in Vigna unguiculata. Journal of Agricultural Science, Cambridge University Press. 128:189-198.
Wang M., Zheng Q., Shen Q., Guo S. 2013. The critical role of potassium in plant stress response. Nanjing Agricultural University, Weigang, Nanjing 210095, China. International Journal of Molecular Sciences, 14:7370-7390.

Wenkert W., Fauscy NR., Watters HD. 1981. Flooding response to Zea mays L. Plant and Soil, 62: 351-366. 